\title{
O mito da cidade moderna e a arte: Torres-García e Xul Solar
}

\author{
MARIA LÚCIA BASTOS KERN*
}

\begin{abstract}
Resumo: A cidade se constitui como o espaço privilegiado para criar a estética da modernidade, visto que ela proporciona novas percepções a respeito das noções de espaço e tempo, permitindo aos artistas absorverem no seu fluxo incessante de mudanças os signos dos novos tempos. O presente artigo tem o fim de analisar as obras de dois artistas modernos platinos - Joaquín Torres-García e Xul Solar - e verificar como a cidade é utilizada para a elaboração das suas poéticas e é concebida e mitificada.
\end{abstract}

Abstract: A city constitutes itself as a privileged space to create aesthetics of modernity, since it provides new perspectives concerning the notion of space and time, allowing so the artists, in its continual flow of changes, to absorb the signs of the new times. The present article has the purpose to analyze the work of two modern Platine artistes, Joaquín Torres-García and Xul Solar, and to verify how a city is used in the elaboration of their new poetics and at the same time, how it has been conceded.

Palavras chave: Modernidade. Cidade. Pintura moderna.

Keywords: Modernity. City. Modern painting.

\section{Introdução}

A cidade se constitui como o espaço privilegiado para a criação da estética da modernidade e os artistas absorverem no seu fluxo incessante os signos dos novos tempos. Pela sua dinamicidade e pluralidade, desde o século XIX, ela tem despertado o interesse de escritores e artistas modernos, proporcionando novas percepções a respeito do espaço e do tempo, concebidos como entidades vivas em constante transformação.

A modernidade possibilita distintas modalidades de experiência vital - experiência do espaço e tempo, do eu e dos outros que são partilhadas pelos homens, sem se limitarem às fronteiras

* Professora do Departamento de História e do Programa de Pós-Graduação em História da PUCRS.

Estudos Ibero-Americanos. PUCRS, v. XXX, n. 2, p. 67-88, dezembro 2004 
nacionais. ${ }^{1}$ A cidade é o espaço no qual a modernidade se constrói e reconstrói de forma recorrente, possibilitando nova sensibilidade diante das cores e dos luminosos da publicidade e da velocidade imprimida pela máquina na sociedade industrial. Ela é o locus em que se processam as mudanças que interferem nos modos de vida cotidiana e provocam nos artistas novas percepções, nutrindo a criação de suas poéticas. Os objetos industrializados penetram na vida e afastam o homem da natureza. Entretanto, eles sensibilizam os artistas pela simplicidade das formas e funcionalidade, germinando investigações estéticas inéditas.

O presente estudo visa analisar os discursos e as práticas artísticas de Joaquín Torres-García e Xul Solar. Dois artistas platinos, uruguaio e argentino, relativamente contemporâneos, cujos olhares sobre a cidade moderna compõem as suas concepções estéticas e suas obras. É de interesse também verificar como eles pensam a cidade e a mitificam.

\section{Joaquín Torres-García}

Analisando os discursos teóricos e as obras do artista uruguaio Joaquín Torres-García (1874-1949) percebe-se que a cidade foi sempre intensamente trabalhada e objeto de suas reflexões para a criação de novas práticas artísticas. Ele faz da cidade, fonte de suas pesquisas com o fim de realizar experiências plásticas, a partir de signos modernos. O espaço urbano também é imaginado pelo artista para construir estruturas sociais mais harmônicas, conduzindo-o a formalizar na pintura e em outras práticas artísticas suportes para a sua "fala mítica". ${ }^{2}$

Nos seus discursos, Torres-García como as vanguardas européias contemporâneas, retomam as reflexões de Walt Whitman, para consagrar a modernidade e o seu caráter de mutação incessante. A máquina e a cidade são os referenciais simbólicos modernos com os quais o artista estrutura a nova arte, em contraposição ao naturalismo, humanismo e à intemporalidade, valores que durante séculos compuseram a tradição clássica.

O presente estudo tem em vista analisar os discursos e representações sobre a cidade, a partir dos livros Universalismo Constructivo (1934-1943) e Una ciudad sin nombre (1941) e da obra plástica de Torres-García, com o fim de verificar os mecanismos de elaboração

1 BERMAN, M. Tudo que é sólido desmancha no ar. São Paulo: Cia. das Letras, 1986, p. 15.

2 BARTHES, Roland. Mitologias. Rio de Janeiro: Difel, 1980, p. 131. 
da linguagem do mito. Entretanto, para se entender a construção do mito e da nova arte, é necessário se recuar no tempo e considerar os primeiros discursos do artista a respeito da cidade, como signo da modernidade, que aparecem em publicações e na sua pintura a partir de 1917, quando vive em Barcelona, e, posteriormente, em Nova Iorque (1920-22), Paris (1926-31) e Montevidéu (1934-49). Posteriormente, vai ser interpretada a pintura do artista argentino Xul Solar (1887-1963), cujas representações demonstram a exaltação da cidade moderna e da estética da máquina, tendo em vista a projeção de novo espaço urbano para Buenos Aires.

No livro El descubrimiento de sí mismo (1917), ${ }^{3}$ Torres-García apresenta um discurso retórico em prol da modernidade e do individualismo em arte, que denota o abandono do ideal tradicional, nacionalista e coletivista que caracterizou a estética do Mediterranismo, ${ }^{4}$ da qual foi seu criador. Neste momento, o seu discurso se peculiariza pela reavaliação de suas idéias teóricas e de sua prática artística, fato que o motiva a declarar a necessidade de esquecer "o passado para ir à felicidade em direção ao desconhecido [...] $\mathrm{O}$ presente é nosso, para poder fazer coisas dignas de virtude. $\mathrm{O}$ futuro é a promessa de algo desconhecido que seria belo descobrir". ${ }^{5}$ $\mathrm{O}$ artista valoriza o presente, porque percebe que a cidade e a máquina são de seu tempo, em detrimento dos valores eternos oriundos do passado, até então cultivados. Nesta época, ele demonstra ter descoberto a modernidade de Barcelona, o seu cosmopolitismo, a sua crescente mecanização, o ritmo dinâmico e a multidão nas ruas, fenômenos que o condicionam a ter uma nova percepção do espaço urbano, que se evidencia no livro mencionado, nas pinturas e desenhos. "Há dois passos daqui uma rua; um formigueiro de gente que se cruza em direção oposta e se perde em mil ruas, que se unem com outras mil. A nossa cidade [...] com o seu porto. Agora acabo de descobri-la, como é bela". 6

$\mathrm{O}$ artista uruguaio não cita em seus textos Baudelaire, mas a sua poética se consolida nesse momento na multidão anônima e no fugaz. Entretanto, o seu olhar sobre a paisagem urbana moderna

3 Partes desta publicação constituem o discurso que Torres-García faz em 1917, na Galeria Dalmau, onde expõe com Rafael Barradas.

4 Mediterranismo/Novecentismo é a estética que surge em 1906 com o fim de construir o universo simbólico nacionalista, recuperando as tradições greco-romanas de modo a concretizar o projeto de autonomia da Catalunha. Os principais teóricos são Eugênio D'Ors e Torres-García. KERN, Maria Lúcia "Os artistas platinos e as vanguardas espanholas". In: JORNADAS DE TEORIA E HISTÓRIA DE LAS ARTES, Buenos Aires: UBA, 1992, p. 19-20.

5 TORRES-GARCÍA, J. Escritos. Montevidéu: Arca, 1974, p. 72.

6 TORRES-GARCÍA, J. Ecrits sobre art. Barcelona: 62, 1986, p. 179. 
não é crítico como é para o poeta francês. Torres-García não representa os tipos sociais e heróis exaltados por Baudelaire, visto a cidade despertar nele mais o encantamento do mundo moderno do que um olhar de condenação. $\mathrm{O}$ artista não representa as ambigüidades que foram tratadas de forma crítica pelo poeta.

Nas novas experiências plásticas e em diversas publicações de 1907 a 1916,7 são desenvolvidas as noções: de plasticismo (antinaturalismo) e estrutura (meio pelo qual ele exprime o seu pensamento) que o artista elabora e pratica de forma metódica com o fim de transformar a sua pintura. A cidade oferece a TorresGarcía a possibilidade de refletir sobre a concepção de estrutura e perceber uma série de novos elementos visuais, como a publicidade, a arquitetura, os luminosos, os meios de transporte, os quais são trabalhados enquanto linguagem plástica. Além desses signos modernos, verifica-se que ele tem consciência das mudanças de sentido das noções de espaço e tempo, quando deixa de lado a narrativa organizada a partir da sucessão de fatos em prol da simultaneidade dos mesmos.

Em História de mi vida (1934), Torres-García afirma que em 1916 começa a pintar coisas simples do cotidiano como objetos e fachadas de casas, e que, posteriormente, se interessa pelas locomotivas, barcos, porto, ruas, lojas e fábricas, "tudo dentro de um grande dinamismo moderno". ${ }^{8}$

A mudança de discurso é rápida e ocorre motivada pela desistência do projeto estético do Mediterranismo, no qual o artista ambiciona colaborar para o agenciamento de uma ordem social mais justa e para a autonomia da Catalunha. Ele abandona, com isto, os murais de grandes dimensões pela pintura de cavalete e ilustrações, em prol de sua independência. "Viu que nada podia fazer coletivamente e por isto preferiu viver só e quis, artisticamente, renovar-se por completo". 9

Nesta época, Torres-García lê pela primeira vez os poemas de Walt Whitman, "Leaves of Grass", tornando-se seu grande admirador e entusiasta do ritmo dinâmico de sua poesia. O poeta americano nessa obra celebra a modernidade de Nova Iorque,

7 "La nostra ordinación el nostre camí" (1907); "Notes sobre art" (1913); "Dialegs" (1914); "Um ensayo de clasicismo" (1916); e vários artigos em periódicos especializados.

8 TORRES-GARCÍA, J. Historia de mi vida. Barcelona: Paidós, 1990, p. 133. É interessante destacar que Léger, nos anos 20, também será sensível às vitrines de lojas e de suas cores. Vide: Funções da pintura. São Paulo: Difel, 1965, p. 68.

9 TORRES-GARCÍA, op. cit., p. 133. 
cantando a multidão nas ruas, a máquina, as novas tecnologias o barco a vapor, o telégrafo, a eletricidade - e a liberdade. Whitman consagra poemas à solidariedade das raças e ao rompimento das fronteiras nacionais. $\mathrm{O}$ interesse pela poesia ocorre no momento em que o uruguaio está abandonando a estética nacionalista e procurando dar nova direção à sua pintura. $\mathrm{O}$ artista que até então não aceitava o caráter cosmopolita das vanguardas passa a cultivá-lo e defendê-lo nos seus textos teóricos.

Em torno de 1916, Torres-García conhece o artista uruguaio, Rafael Barradas, que após o contato com o Futurismo na Itália e o Cubismo na França, chega a Barcelona e cria o "Vibracionismo", 10 utilizando como fonte de experiência plástica a cidade, com os seus signos dinâmicos modernos. A sua obra exerce um grande fascínio em Torres-García, graças à plasticidade e ao papel de conscientização que a mesma oferece. Nesta época, ele executa também algumas pinturas vibracionistas, como, por exemplo, a tela de 1918 com igual denominação, na qual apresenta uma nova percepção do espaço urbano e do tempo. Agora, as formas fragmentadas e sobrepostas denotam a velocidade do mundo mecanizado e da vida do homem na cidade. Os relógios marcam o tempo presente, enquanto as letras e os números tipográficos assumem a plasticidade e simbolizam a objetividade racional da era da produção industrial em série.

Segundo Torres-García, "Barcelona estava inédita e nós (ele e Barradas) fomos os primeiros a descobrir". A nova percepção da cidade e a prática artística conduzem o artista a redigir em 1917, o primeiro manifesto em defesa da modernidade na Espanha. Em Art Evolució (A Manera de Manifest), proclama que "Nossa divisa tem de ser: individualismo, presentismo e internacionalismo". O manifesto salienta ainda a necessidade de evoluir constantemente e ser atual, pois isto significa, para o autor, que o seu "papel consistiria unicamente em assinalar a plasticidade do seu tempo". ${ }^{11}$ A busca do efêmero e do presente fugidio é o meio pelo qual o artista estabelece a relação de sua obra com o real e de construção plástica da nova paisagem urbana.

10 Segundo Barradas, o Vibracionismo é essa emotividade nervosa do espírito que mistura a simultaneidade de sensações novas. IGNÁCIOS, Antonio de. Historia de Rafael Barradas. Montevidéu: [s.n.], 1953, p. 62.

11 PELUFFO, Gabriel. Torres-García: de Barcelona a Paris. In: Historia de la pintura uruguaya. Montevidéu: Galeria Sur, 1992, p. 191. 


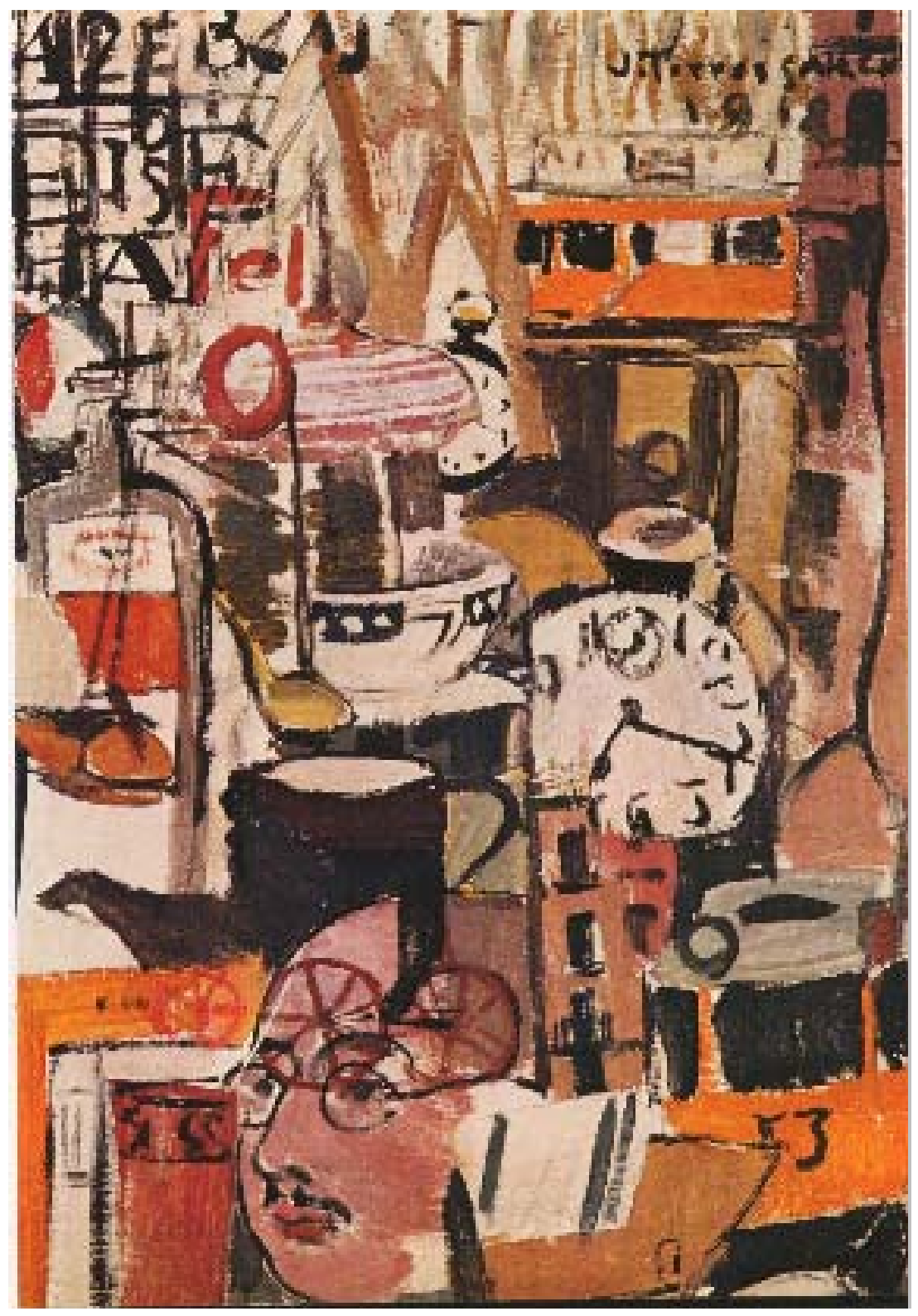

J. Torres-García. Composición vibracionista, 1918. Óleo sobre tela, 50 x $35 \mathrm{~cm}$. Coleção de Joan Llorens Gardí. Barcelona.

In: Torres-García. Madrid: Museu Nacional Centro de Arte Reina Sofia, Ministério da Cultura, 1991, p. 54. 
A cidade de Torres-García é um mito; ela não tem passado histórico, apenas o presente transitório com todos os seus signos modernos. O mito representa o lugar em que ele pensa, pesquisa e pratica a nova concepção de arte, bem como é o meio pelo qual o artista procura dar outro sentido à realidade. As pinturas sobre Barcelona ao celebrarem o moderno, têm também em vista evidenciá-lo no espaço da tela. As formas tornam-se mais depuradas e dinâmicas, revelando a sua busca de síntese, presente nas formas das máquinas. A estrutura ortogonal vai fundamentar mais tarde a sua pintura construtivista e começa a aparecer progressivamente, sobretudo, nos desenhos e ilustrações. Ela ordena e hierarquiza o espaço urbano e o configura de modo racional, porém atrelada à sua visão mítica.

A concepção de cidade do artista uruguaio, de 1917 a 1920, em Barcelona é idealizada, visto que situa a ordem na multiplicidade de imagens, submetendo a representação da mesma à harmonia por ele desejada. A pureza formal é encontrada na geometria da estrutura da cidade e da máquina. Em carta a Barradas, Torres-García declara: "Percebo agora, e você também [...] perceberá, que a nova lei que vai criando as modernas formas da mecânica é a que cria as novas formas da arte, e as novas cidades, e tudo, e eu me sinto uma roda nessa engrenagem". ${ }^{12}$ A lei que TorresGarcía menciona é a da transformação constante e desenvolvimento tecnológico que induz as mudanças na vida cotidiana, na arte e na cidade. 13

A consagração do espaço urbano moderno e da máquina justifica-se para o artista, como para muitos intelectuais de seu tempo, na esperança de resolução da crise que passa a Europa do pós I Guerra Mundial. Diante do caos, eles aspiram à ordenação e a harmonia social. Apesar de Torres-García, ao longo de sua trajetória, assumir comportamentos messiânicos, neste momento, revelase grande entusiasta da mecanização ao procurar estabelecer um vínculo mais profundo entre a arte e a produção, começando fabricar brinquedos infantis em série. ${ }^{14}$ A produção destes brinquedos indica a preocupação do artista em aliar as novas pesquisas visuais às condições práticas da existência, valorizando assim a industrialização, o design e o espírito pragmático moderno.

12 PELUFFO, op. cit., 1992, p. 141.

13 A forma geométrica é consagrada pelos artistas por sua pureza e meio de ordenação do espaço plástico.

14 Esses se configuram como pequenas esculturas em madeira policromadas e, às vezes articuladas, que representam os seus experimentos plásticos em torno da síntese formal e do frontalismo. 
Torres-García estabelece um programa de ação, no qual enfatiza o papel do artista, destacando que cabe a este "eternizar o atual", e descobrir o universal no particular. Ele procura conciliar a sua visão idealista com os valores efêmeros da modernidade e o pragmatismo do espírito moderno. Este ideal é transplantado para a sua fala mítica sobre a cidade, por meio da ordenação plástica que, é acentuada pelo uso progressivo da estrutura ortogonal e da hierarquização dos signos por ele selecionados. Torres-García configura assim a cidade, segundo a sua concepção de plasticidade num exercício dialético entre o real e o formal.

Em 1917, quando ele expõe com Barradas as pinturas de temática urbana, em Barcelona, declara a dificuldade que os dois tiveram para criar títulos para as mesmas: "dificuldade para expressar por meio da palavra [...] aquilo que, para nomeá-lo adequadamente, é puro Plasticismo [...]. Muitos trabalhos [...] não deveriam levar título algum. [...] Porque no fundo, se trata de resolver unicamente um problema plástico". ${ }^{15} \mathrm{O}$ plasticismo é concebido como elemento essencial da modernidade estética e como meio para atingir a autonomia da arte, fazendo da obra o próprio fato plástico. E o meio pelo qual ele ambiciona atingir a pureza formal e a verdade, em detrimento da representação ilusionista.

Em 1920, ele decide viver em Nova Iorque motivado pelo "desejo de ver uma grande cidade moderna"16 e mecanizada, pois acredita que esta poderia oferecer melhores condições para implantar a indústria de brinquedos, cujo projeto fracassara em Barcelona. O objeto industrial moderno representa a maior concorrência sofrida pelo artista. ${ }^{17}$ Torres-García procura enfrentar essa concorrência e acha também que teria maiores oportunidades, como artista moderno, nessa cidade avançada em termos técnicos, arquitetônicos e urbanísticos.

Ao chegar a Nova Iorque, Torres-García se deslumbra: "Que vida! Que movimento! tudo é mecânico, ordenado, limpo [...]! Esta é a civilização [...] Oh, que velha e triste é a Europa! Lá encontra-se toda aquela gente meio corroída com suas misérias [...]". ${ }_{18}$ Percebe-se a euforia do artista em relação à cidade norteamericana, símbolo de progresso e de futuro, em face à crise que vive a Europa do pós-guerra. Ele executa no período que lá resi-

15 LUBAR, Robert. Art-evolució: Joaquin Torres-García y la formación social de la vanguardia en Barcelona. In: Barradas, Torres-García. Madri: Galeria Osma, 1991, p. 27.

16 TORRES-GARCIA, op. cit., 1990, p. 144.

17 LÉGER, op. cit., p. 63.

18 TORRES-GARCIA, op. cit., 1990, p. 151. 
de (1920-1922) uma série de pinturas, um álbum de desenhos e aquarelas. Nos desenhos, o nome da cidade aparece sempre em caixa alta, de modo a constituir parte da composição. A forma geométrica e as superfícies chapadas se acentuam, apresentando, às vezes, o frontalismo, como "Escena de calle" (1921); outras vezes, amplas perspectivas que destacam as grandes avenidas e seus arranha-céus. A estrutura ortogonal, compartimentada é também freqüente. Segundo o uruguaio, é uma "pintura de ritmos livres, porém já com domínio de vertical e horizontal", que auxiliam na ordenação objetiva da forma. Ele realiza várias telas sobre o cenário luminoso da Brodway, que acredita representar "center of the world".19

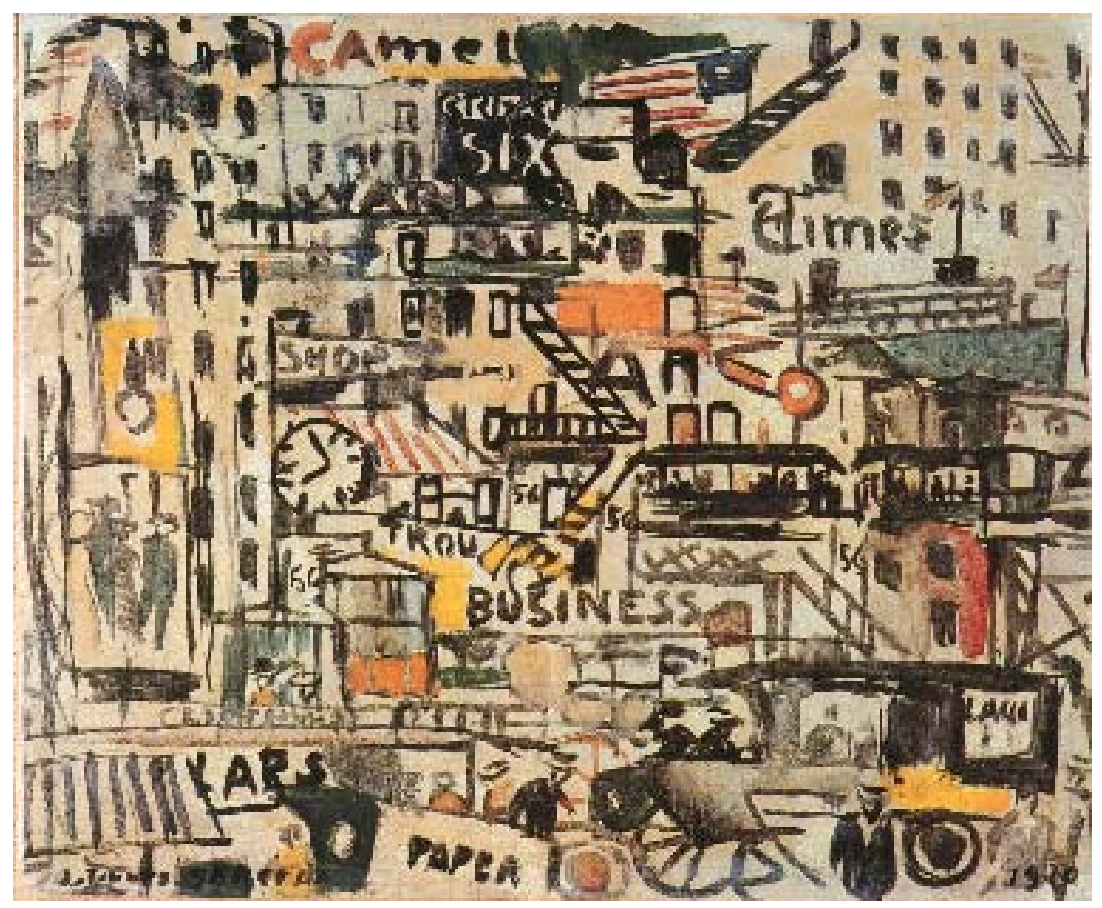

J. Torres-Garcia. Paisaje de Nueva York, 1920. Óleo sobre cartão, 45,7 x 58,4 $\mathrm{cm}$. Coleção particular.

In: Torres-García. Madrid: Museu Nacional Centro de Arte Reina Sofia, Ministério da Cultura, 1991, p. 57.

19 TORRES-GARCIA, op. cit., 1990, p. 151. 
Torres-García em carta a Barradas expressa o seu deslumbramento: "Nova Iorque é minha cidade; por isto agora sou imensamente rico: milhões de imagens sonhadas e desejadas [...] Minha cidade, a cidade mais cidade". ${ }^{20}$ No entanto, a euforia inicial cede lugar ao desânimo, porque seus projetos não são bem sucedidos. Em 1922, começa o caderno "Goodbye New York", no qual executa desenhos coloridos, que evidenciam a decisão de voltar para a Europa. Esta medida foi motivada pela tentativa fracassada de industrializar os brinquedos em madeira policromada. TorresGarcía constata ainda que o ambiente artístico nova-iorquino não é o desejado, pois teria que renunciar a si mesmo, num momento em que acredita que deveria manter a sua identidade pessoal. As experiências que teve nesta cidade, foram no sentido de direcionamento de seu trabalho, o que lhe desagradou muito. ${ }^{21}$

Neste momento de pessimismo, o artista sustenta que a moderna cidade de Nova Iorque, ao mesmo tempo, que o atrai, o repele. Para ele, ir embora representa sua libertação, apesar de deixar uma "civilização materialista acabadíssima". ${ }^{22}$ Ele retorna a Europa em busca da alma e do espírito, valores que não encontra na América do Norte, valores oriundos da velha tradição humanista.

A experiência em Nova Iorque condiciona o artista a repensar a sua fala mítica e ufanista sobre os centros urbanos. A verticalização acentuada e a primazia de valores materialistas sobre os espirituais assustam Torres-García. A concepção de cidade que vai desenvolver no final dos anos 20, em Paris e, posteriormente, em Montevidéu é totalmente diversa. Não é mais uma cidade que serve como modelo - Paris, Barcelona ou Montevidéu - mas a cidade desejada e imaginada de forma mítica. O novo espaço urbano é quase abstrato e humanista, sem apresentar um lugar definido e particularizado. Ele é idealizado tendo como modelo a ordem clássica e o pensamento idealista, em face à multiplicidade, à fragmentação e à mecanização das cidades modernas.

As idéias que fundamentam o livro Universalismo Constructi$v 0^{23}$ e a sua prática artística emergem em Paris, a partir de 1928, quando Torres-García acentua a construção formal, dissociando o

20 PELUFFO, op. cit., 1992, p. 142.

21 TORRES-GARCÍA, op. cit., 1990, p. 170.

22 TORRES-GARCÍA, op. cit., 1990, p. 170-2.

23 Os conceitos básicos do Universalismo Constructivo foram extraídos e mais desenvolvidos pela autora em "Universalismo Constructivo e suas aspirações utópicas". In: ANAIS DA V JORNADAS DE TEORIA DE LAS ARTES, Buenos Aires, CAIA, Univ. Buenos Aires, 1993, p. 97-104. 
desenho dos planos de cor. A pintura não apresenta mais o ritmo dinâmico do cenário urbano, mas a sua ordenação geométrica e o sentido de estabilidade, com a pemanência dos signos modernos, tais como máquinas e fábricas. Como por exemplo, a tela "Pintura construtiva", (1929). Tanto a arquitetura urbana como a máquina evidenciam a presença de formas geométricas puras. A simetria é uma tradição da qual ele não consegue abandonar.

Torres-García trabalha em Montevidéu, no seu livro o Universalismo Constructivo - Contribuición a la unificación del arte y la de América (1934-1943) com os conceitos de classicismo, plasticismo e estrutura, resultantes das suas reflexões teóricas e obra plástica. A sua visão de clássico é muito própria, pois significa ao mesmo tempo o "verdadeiro equilíbrio, aquele em que predomina a idéia sobre o sentimento [...] com sujeição a uma ordem [...] dentro das leis da harmonia"; "realidades concretas ${ }^{24}$ e ordenadas" e a arte arcaica. ${ }^{25}$

A arte construtiva, segundo Torres-García, adota os aspectos modernos, como a síntese formal, por exemplo, mas sem deixar de lado os cânones da tradição clássica - o ritmo e o conceito puro de forma - assim como o frontalismo de origem arcaica. Para ele, estas questões formais imprimem na obra o caráter universal e permitem o desenvolvimento das noções de plasticismo e estrutura.

A retomada da disciplina e ordem clássicas se insere no panorama do Retour à l'ordre, na França do pós-guerra, quando os artistas propõem a volta à tradição como meio de controle da modernidade e da ação das vanguardas que têm em vista a constante revolução estética. A fala mítica de Torres-García sobre a cidade se integra nesse projeto de ordenação e controle das mudanças, como mecanismo de construção de uma ordem social ideal e mais estável, na qual predominaria a harmonia e certa homogeneidade de valores e práticas artísticas.

Para ele, a estrutura da obra se formaliza num conjunto plástico na unidade, "um todo harmônico", 26 no qual não se deve acrescentar nada porque seria secundário, e nem mesmo retirar. TorresGarcía concebe a estrutura como geradora da obra e a identifica com a construção arquitetônica, isto é, a geometria e a medida. A estrutura permite, assim, atingir a unidade perfeita e a arte universal e, ao mesmo tempo, manter os valores perenes e intemporais. Entretanto, a idéia de estrutura também é originária de signos modernos, como

24 As realidades concretas seriam as próprias pinturas, visto que se constituem em fatos plásticos independentes de representações empíricas.

25 TORRES-GARCIA, J. Universalismo Constructivo. Madri: Alianza, 1984, p. 662, 697, 698.

26 TORRES-GARCÍA, op. cit., 1984, p. 663. 
a máquina e a cidade. A máquina atrai a atenção do artista, pela sua funcionalidade e precisão; e a cidade pelo sentimento de geometria que desperta e pela combinação de elementos distintos, que se integram entre si de forma equilibrada, segundo a sua ótica. A fragmentação, a multidão e o ritmo dinâmico do espaço urbano são fenômenos destacados pelo artista para justificar a sua postura antinaturalista e a sua visão de arte moderna.

O espaço urbano sugere a Torres-García a integração das diferentes partes no todo, por meio de formas primárias e o sentido unitário, sendo por isso utilizado como modelo plástico ideal. $\mathrm{O}$ artista apresenta uma visão otimista do espaço urbano, como outros artistas construtivistas, que o idealizam. Esse espaço não existe, é um mito. Ele não é unitário, mas fragmentado e múltiplo. A cidade também sugere ao artista outros elementos na ordem plástica, que são as letras e os números, os quais assumem o papel de estruturar pelo efeito de repetição que produzem na pintura.

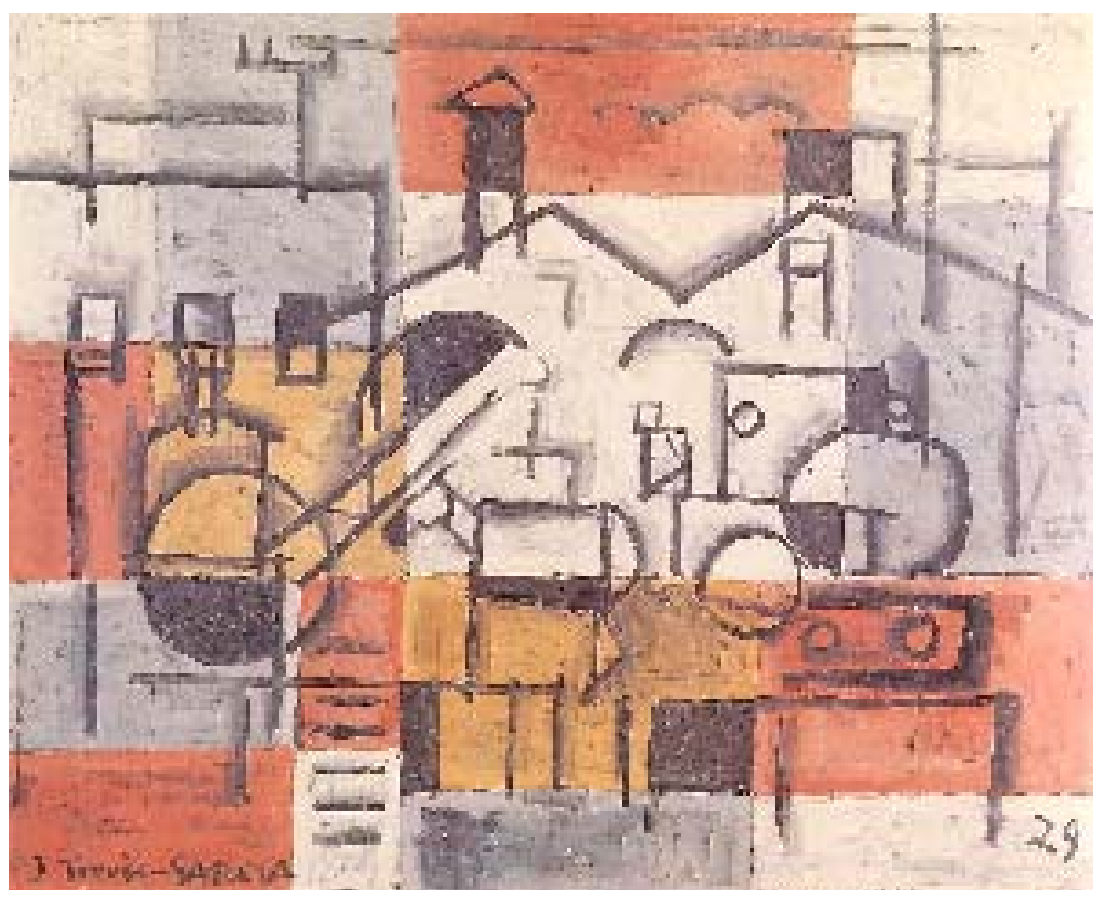

J. Torres-García. Pintura constructiva, 1929. Óleo sobre madeira, 80 x $100 \mathrm{~cm}$. Coleção Museu de Artes Visuais, Montevidéu.

In: Torres-García. Madrid: Museu Nacional Centro de Arte Reina Sofia, Ministério da Cultura, 1991, p. 86. 
Se por um lado, a cidade e a máquina servem como modelo de especulação estética; por outro, nessa a individualidade se dissolve, e cede espaço para o coletivo. A visão liberal do artista é abandonada em prol do coletivo e da ordem estética, que exigem o seguimento de princípios plásticos pré-estabelecidos. O valor universal em voga entre os artistas, nesta época, é outro fator que termina em parte com o individualismo, quando este último começa a ser visto pelos Estados Totalitários como fenômeno motivador da desordem e da anarquia. Por isto, a cidade de Torres-García não é identificada, sendo concebida como um espaço quase abstrato, cujas formas são estáticas, frontais e ordenadas pela estrutura ortogonal. $\mathrm{O}$ artista radicaliza $\mathrm{o}$ conceito de construção, oriundo da arquitetura, reduzindo as figuras a ideogramas, que combinados com números, letras e signos modernos procuram simbolizar a nova cidade humanista. A estrutura permite a reunião de valores perenes, eternos e intemporais, de teor universal, com valores efêmeros e temporais da modernidade.

Ao explicar como desenvolve a sua pesquisa plástica para criar o Universalismo Constructivo, Torres-García afirma que "Tinha que ordenar esse mundo que agora, parecia um caos". ${ }^{27}$ Assim, a sua cidade é o mito oriundo da negação da cidade real e da aspiração idealizada em criar um mundo melhor. Ela não é produzida em cima de dados objetivos da realidade urbana moderna, nem de sua história. A multiplicidade do espaço, sua fragmentação e suas contradições são artificialmente ordenadas, no espaço bidimensional da tela, para emergir a cidade humanista, sonhada pelo artista. TorresGarcía projeta a recomposição do mundo moderno e o Universalismo Constructivo, revela o seu pensamento identificado com a visão humanista da cidade, extraindo da mesma o seu caráter dinâmico e de mudanças incessantes. Como afirma Argan, "a cidade ideal nada mais é que um ponto de referência em relação ao qual se medem os problemas da cidade real". 28

Torres-García saiu de Montevidéu, ainda jovem, em 1891. Quando retorna em 1934, mostra-se encantado com a sua cidade, por ter um caráter único que a torna inconfundível: casas baixas e ruas largas que permitem a abundância de luz e o maior alcance visual do espaço urbano. A luz é para ele branca e luminosa. A arte dessa cidade deve ser construída, "planista e bidimensional, esquemática e sintética; arte de grandes ritmos e estreitamente ligada à arquitetura". 29

TORRES-GARCÍA, op. cit., 1990, p. 211.

28 ARGAN, G. História da arte como história da cidade. São Paulo: Martins Fontes, 1992, p. 73.

29 TORRES-GARCÍA, J. La escuela del Sur. Lección 20. In: Universalismo Constructivo y la escuela del Sur. Washington: Museo de Arte de las Américas, 1996, p. 47. 
A concepção de cidade mais humana, pensada na última etapa de sua estadia na Europa, vai ser expressa no seu livro La ciudad sin nombre (1941), escrito em Montevidéu e tendo este local como cenário. Identifica-se a localidade pelo fato do artista apresentar espaços tradicionais e modernos da capital uruguaia em contraponto a uma produção plástica conservadora, que condiciona o autor a explicar as razões dele ter voltado ao país: "levantar a arte, criar uma nova com ciência, buscar a tradição profunda". 30

Torres-García analisa os espaços urbanos estabelecendo paralelos com a sua visão de arte, bem como revelando a configuração dos mesmos a partir da plasticidade que esses despertam. "Que coisa(s) maravilhosa(s) são as ruas! [...]. Impressão plástica que seria interessantíssima para um artista moderno. Mil formas em movimento incessante. Superfícies enormes com mil aberturas retangulares [...] mais anúncios [...] veículos [...]". ${ }^{31}$ Além da plasticidade apreendida na dinâmica e pluralidade urbana moderna, o artista uruguaio valoriza a tradição ao salientar a beleza e a identidade dos bairros antigos em confronto com aqueles modernos. Para ele, os últimos não têm caráter já que o comércio uniformizou as cidades, com as mesmas propagandas, os mesmos tipos de lojas e de vitrines, etc. Houve uma estandartização do espaço e dos transeuntes que começa a ser observada pelo artista.

Percebe-se no seu pensamento o abandono da visão acrítica a respeito da modernidade e a preocupação de retomar as origens com o fim de construir uma arte própria para a América, assim como recuperar a relação entre a arte, vida e sagrado. É neste sentido que ele propõe reconstruir o pensamento primitivo, voltando ao conceito de mundo e de vida pré-colombiano, anterior à conquista do continente, em que a arte se integrava à vida cotidiana e à noção de cosmos. A nova plástica é denominada por Torres-García de Cosmoplastia porque "respeitando a superfície da tela, [...] considera só o plano de cor e a forma, que terá um valor por si mesmo e não referência a alguma coisa; e tudo isto medido e em função da ortogonal". ${ }^{32}$ Verifica-se que ele une a sua visão de cosmos com aspectos plásticos do Universalismo Constructivo, o qual foi formalizado por meio de seu olhar sobre a cidade.

30 TORRES-GARCÍA, J. La ciudad sin nombre. Montevidéu, 1941. s.p. Esta publicação é escrita à mão e desenhada pelo próprio artista. No final da mesma, ele afirma que se encontra em Montevidéu, apesar do título.

31 TORRES-GARCÍA, op. cit., 1941, s.p.

32 TORRES-GARCÍA, op. cit., 1941, s.p. 
Neste momento, em Montevidéu, a sua concepção de modernidade estética vincula-se às culturas pré-colombianas e aos símbolos arcaicos, já pesquisados quando vivia em Paris, que aliados aos conceitos estéticos do Universalismo Constructivo fundamentam a sua prática artística. A partir da construção do novo tendo por base o passado, Torres-García aspira erigir uma arte própria e total para a América, independente da arte européia.

\section{Xul Solar}

Outro artista que é sensível à cidade é o argentino Xul Solar (1887-1963), ${ }^{33}$ que como Torres-García tem aspirações de atingir o absoluto através de suas pinturas.

A sua trajetória inicial é marcada pela crise espiritual e necessidade de fugir de seu mundo, fenômenos que se definem paulatinamente na configuração da sua pintura. As representações simbólicas, recorrentes em sua obra, revelam, quando ainda vive em Buenos Aires, as fantasias e a constante procura de algo metafísico que ele tenta descobrir, já que não encontra na ciência respostas satisfatórias para as suas indagações. ${ }^{34}$ À medida que amadurece e entra em contato com as vanguardas e místicos europeus, ele procura integrar o sagrado com o profano, assumindo a sua pintura proporções éticas e proféticas.

Xul Solar desde as suas primeiras experiências de teor simbolista, em Buenos Aires, navega num universo oculto e fantasioso, revelando o interesse em desvelá-lo. Posteriormente, em 1917, quando vai residir em Milão, executa uma série de pinturas, cujo tema central é a arquitetura observada nessa cidade e revestida de aspectos imaginários, emoldurada por símbolos esotéricos. Neste momento, ele cria um conjunto de aquarelas, de pequenas dimensões, que têm como modelo inicial a Catedral de Milão, como se pode evidenciar em "Estilo 3" (1918) e "Catedral" (1918), obras em que o artista mescla elementos compositivos góticos, orientais e da arquitetura da Sagrada Família de Gaudi. ${ }^{35}$ Nestas pinturas, as

33 Deve-se destacar que em 1916, o artista Oscar Alejandro Augustín Schulz Solari passa a assinar Xul - inverso de Lux - Solar - Sol. O seu novo nome relaciona-se provavelmente com o seu conhecimento das religiões orientais e do misticismo, já que a luz e o sol representam o mundo divino e a espiritualidade, em oposição ao caos e à obscuridade.

34 Em 1912, Xul embarca num navio com o fim de ir ao Tibet e entrar na vida monástica, porém acabou desembarcando em Londres.

35 Deve-se destacar que Xul estuda arquitetura na Universidade de Buenos Aires, antes de ir para a Europa. Esta formação está muito presente no conjunto de sua obra. 
formas são irregulares e planas, as cores escuras e chapadas, as quais atribuem um aspecto sombrio e obscuro às mesmas. Xul libera a sua fantasia e imaginação, construindo fachadas de edifícios rodeadas por símbolos oriundos de antigas religiões orientais, mesclados por fragmentos arquitetônicos, como capitéis de colunas e elementos decorativos. Em 1919, ele introduz palavras na pintura e posteriormente textos em neocriollo, língua criada pelo artista que mescla termos e sílabas do português e do espanhol modificados. ${ }^{36}$

Apesar dele buscar na arquitetura de Milão os temas de suas aquarelas, observa-se a presença de um mundo oculto interior, no qual ele se encontra submerso. Nos cenários teatrais pintados a partir de 1920, as formas geométricas planimétricas dominam o espaço, estruturado de forma objetiva e intemporal. Essas formas são coloridas e dinâmicas, constituindo-se como meios líricos de expressão. Verifica-se a maior liberdade no uso de cores intensas e nos jogos sutis de tonalidades e transparências. As formas simbólicas continuam presentes, como por exemplo, na aquarela "Escena" (1924), impregnada pela luz solar ascendente, ladeada pelo astro e pela virgem. Esses símbolos, como a luz, conferem o sentido de espiritualidade e elevação.

Na ótica de alguns artistas modernos, como por exemplo, Paul Klee, ${ }^{37}$ a arquitetura se identifica com a noção de novo mundo espiritual, possibilitando a elevação ao domínio absoluto. Verifica-se que os artistas constroem o mito do sagrado a partir do pensamento dualista, no qual contrapõem o terreno/material ao absoluto, abandonando assim o mundo real e recorrendo aos símbolos arcaicos de teor místico. Assim, eles acreditam exprimir as diferenças entre os dois mundos: profano e sagrado.

Xul viaja a Londres (1919), 38 naquele momento reconhecido como centro espiritual e místico, e faz breves estadias, várias vezes, em Paris, Florença, Milão e Turim, onde mantém contato com o Cubismo e o Futurismo. Apesar de conviver com esses movimentos de vanguarda, nas aquarelas ele representa o seu mundo imaginário, construído tendo por base as suas crenças e as formas geométricas

36 O neocriollo é fruto de seu desejo de unidade lingüística na América Latina. Depoimento do artista em 01/08/1951 para o Mundo Argentino, s.p. Porém, a unidade ambicionada, segundo a sua visão, poderia se concretizar também por meio da retomada dos valores simbólicos arcaicos pré-colombianos e da sua elevação espiritual.

37 Xul conhece as pinturas de Klee, provavelmente, em Munique e as admira muito. Tanto Klee, como Kandinsky e Mondrian almejavam através de suas obras atingirem o absoluto.

38 Em Londres, ele reside durante seis meses. 
puras que flutuam no espaço plástico, no qual as luzes, transparências e cores acentuam os aspectos líricos. 39

Tanto o espírito místico quanto as formas geométricas evidenciam o desejo de purificação de Xul e Torres-García, bem como a busca de essência. Ao apreendê-la, eles pensam poder captar a realidade concreta e expressarem de forma compreensível os valores espirituais. Com os símbolos, eles têm em vista retomar a origem e a essência de toda a manifestação cultural, daí o movimento de busca de unidade e, ao mesmo tempo, de expressão dos acontecimentos da alma que são próprios da crise espiritual vivenciada pelo homem na modernidade.

Em 1924, Xul volta a Buenos Aires, depois de ter ido a Munique, trazendo uma série de livros monográficos sobre artistas modernos e temas místicos, ${ }^{40}$ convicto de que através de suas pinturas poderia ordenar o cosmos e difundir valores espirituais elevados. Neste momento, intensifica os estudos sobre Astrologia e diferentes crenças ocidentais e orientais, assim como em relação às culturas pré-colombianas. Começa, então, a mesclar os símbolos de distintas procedências místicas com o fim de comunicar ao público a noção de unidade, ordem espiritual e inteligibilidade do cosmos. Observa-se que o artista argentino procura através de suas aquarelas atingir o mundo divino, utilizando formas ascensionais direcionadas à purificação (do mesmo modo que Torres-García) e à reconquista de valores morais degradados. Esta procura acompanha praticamente toda a sua trajetória como artista, e pode-se verificar que a mesma está marcada por preocupações de teor ético. ${ }^{41}$ Xul presencia a guerra na Europa e vivencia o debate dos artistas, após o conflito, a respeito das novas funções sociais que a arte deveria exercer no momento de reconstrução. Daí a sua constante preocupação em produzir uma obra que permita a ordenação do mundo no futuro.

39 Já Hegel, acredita que o colorido dá alma e vida à pintura e valoriza a sua imaterialidade e capacidade expressiva. Goethe, na sua teoria das cores, afirma a subjetividade e a relação das mesmas tanto com a luminosidade, quanto com a obscuridade. As suas idéias se fundamentam na dialética entre a transparência e a opacidade, sendo as mesmas seguidas pelos artistas modernos.

40 Ele adquire livros sobre filosofia, como os escritos por Nietzsche, sobre numerologia, Teosofia e religiões orientais, tais como os de autoria de Eric Bischoff, Helena Blawatsky, Rudolf Steiner, etc. Dentre os livros de arte destaca-se a monografia sobre Paul Klee, de autoria de Leopold Zahn. As suas ascendências alemã e italiana, aliadas à facilidade em apreender idiomas, possibilitam que ele faça leituras nestas línguas e no inglês.

41 Klee no seu Journal afirma em 1900: «Diante de seu poder soberano eu queria subsistir e subsistir de modo ético. In: Journal. Paris: Bernard Grasset, 1995, p. 45. 
Ele ingressa no grupo de escritores e artistas da revista Martín Fierro (1924-27) com o objetivo de difundir a arte moderna e seus fundamentos teóricos ao público argentino. Nesta revista são publicados artigos a respeito da arquitetura racional, textos de Le Corbusier e da revista L'Esprit Nouveau, sensíveis aos ensinamentos da mecanização moderna. A pintura de Xul começa a representar de modo recorrente o espaço urbano, assim como diversos escritores de Martín Fierro o fazem em obras literárias, como Jorge Luis Borges, Oliverio Girondo e Roberto Arlt. O último tem um olhar mais crítico, que não está presente na pintura do argentino.

Em 1925, Xul retrata a cidade estruturada em arranha-céus, povoados de figuras imaginárias e símbolos arcaicos e místicos, dentre os quais se destacam as escadas que conectam o espaço terreno com um espaço superior. "Doce escaleras" e "Pagoda" (1925) são pinturas cujas formas geométricas são construídas por planos ordenados de modo ascensional e pelo jogo de cores que configuram a sua imaginação lírica a respeito das relações do homem moderno com o espaço urbano e o universo espiritual.

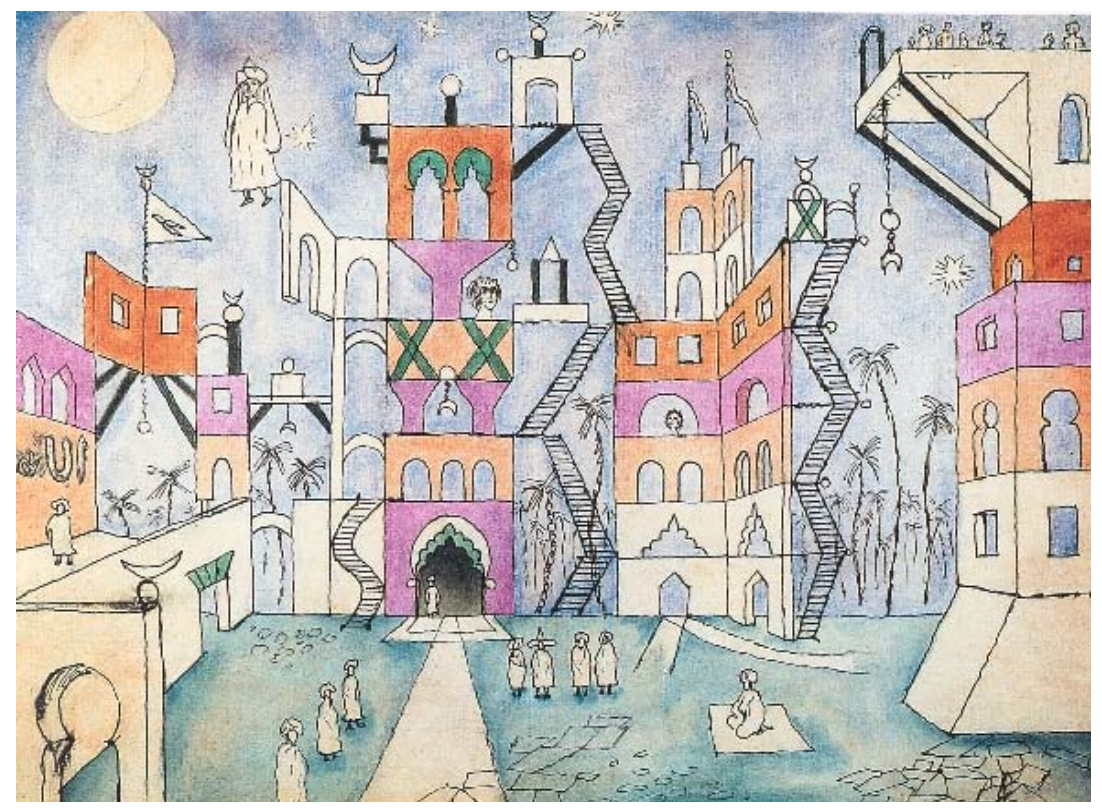

Xul Solar. Pagoda, 1925. Tinta e aquarela, $28 \times 37 \mathrm{~cm}$. Coleção particular. In: Xul Solar. Buenos Aires: Museu Nacional de Belas Artes, Secretaria de Cultura, 1998, p. 51. 
A cidade do argentino é moderna, verticalizada, estruturada por longas avenidas e repleta de aviões, máquinas voadoras, transatlânticos e seres estranhos. Xul configura o espaço urbano, em geral, de forma frontalista, representando a multidão e as bandeiras de distintas nacionalidades que revelam o cosmopolitismo do mesmo, porém sem deixar de conectá-lo com a sua imaginação mística ao inserir símbolos de diferentes conviç̧ões religiosas. Como se pode verificar em "El túnel" (1924), "Vías" (1925), "Puerto Azul" (1927), "Buenos Aires" (1929), etc. Verifica-se que o artista é sensível às novas tecnologias e máquinas modernas, assim como à arquitetura dos grandes centros urbanos. As suas cidades, geralmente, não têm passado, mas apenas presente e projeções futuras, como as aquarelas "Projecto de fachada para a cidade" e a série "Proyecto fachada Delta" (1954), bairro de Buenos Aires. Elas são habitadas por seres fantásticos, edificações e ordenadas, fatos que denotam o seu otimismo em relação aos espaços urbanos modernos. Os espaços plásticos transitam da bidimensionalidade à terceira dimensão. As figuras e símbolos não são representados de modo simultâneo, mas ocupam os seus lugares de forma organizada.

Para Beatriz Sarlo, Xul ao propor a ordem geométrica visual à pluralidade caótica da cidade moderna, confia na capacidade organizativa do espaço para sintetizar elementos conflitivos de origens diferentes. A cidade, campo de batalha simbólica, pode se constituir também como espaço de resolução da mescla.42 Do mesmo modo que o grupo Martín Fierro, Xul defende a integração social e étnica, num momento em que os intelectuais em Buenos Aires temem a forte presença imigratória, o cosmopolitismo e a dissolução das tradições culturais argentinas. Xul mescla em suas aquarelas signos da modernidade com aqueles das tradições nacionais e latino-americanas.

Ele não considera o crescimento desmesurado de Buenos Aires após a chegada de imigrantes europeus, nem as tensões sociais e culturais. Só a população de italianos permite o crescimento da cidade, na ordem $75 \%$. "Eriçada de torres, a cidade proclama nas alturas o vigor de um povo. Já tem a coroa cinzenta das grandes metrópoles, cinza de fumaça [...], hoje também sacudidos pelo dinamismo característico do povo portenho". ${ }^{43}$

42 SARLO, B. Borges, um escritor em las orillas. Buenos Aires: Seix Barral, 2003, p. 31.

43 Caras y Caretas, out. 1930. In: SARLO, B. Paisagens imaginárias. São Paulo: Edusp, 1997, p. 199-201. 


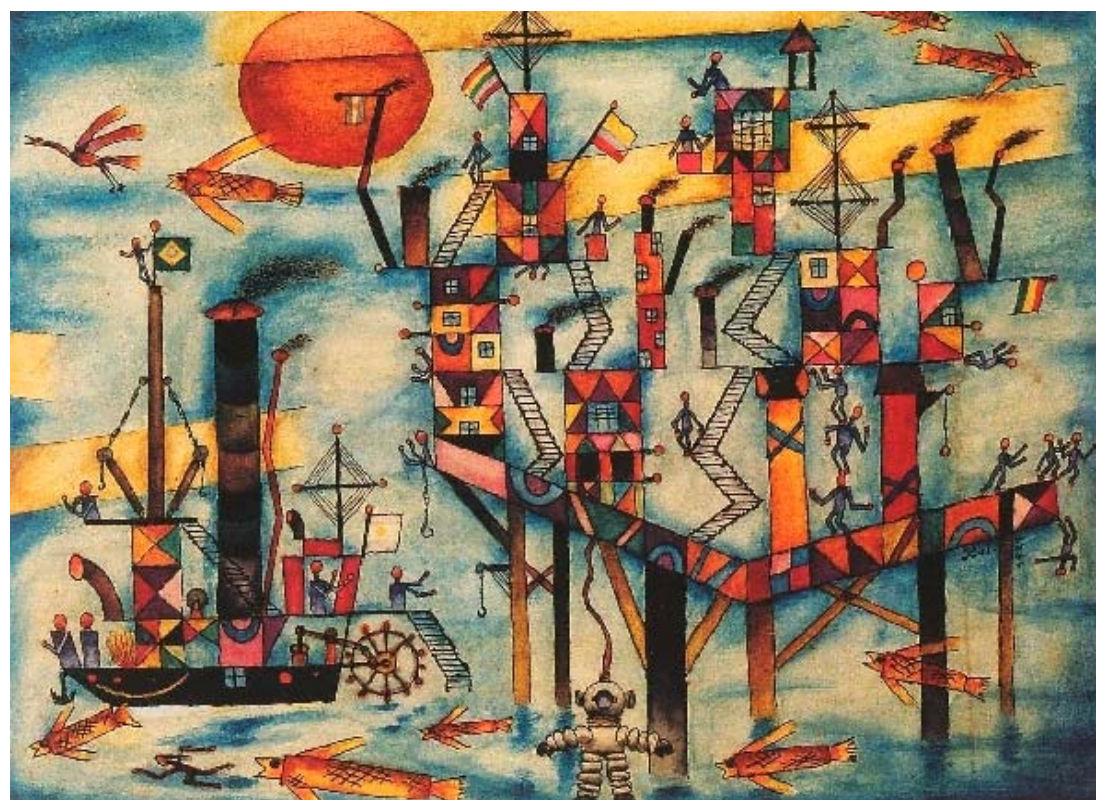

Xul Solar. Puerto Azul, 1927. Aquarela, 28 x 37 cm. Coleção do Museu Xul Solar.

In: Xul Solar. Buenos Aires: Museu Nacional de Belas Artes, Secretaria de Cultura, 1998, p. 67.

Os intelectuais nacionalistas, como Rojas, resistem ao moderno, se inquietam diante da pluralidade, das tensões sociais e culturais geradas pela imigração. ${ }^{44}$ Eles temem que a introdução de idéias, valores e costumes estrangeiros levasse à dissolução dos ideais de nação, das tradições argentinas e da coesão social. Rojas defende como solução, integrar as populações nativas gaúcha, criolla de origem espanhola e indígena com os imigrantes. Já os escritores Leopoldo Lugones e Manuel Gálvez percebem a ameaça da idiosincrasia cultural pela pressão lingüística, cultural e ideológica do imigrante. Com isto, eles projetam o mito da raça sem mescla para evitar, assim, a degradação cultural.

44 Entre 1891 e 1914, a Argentina absorveu 17\% da imigração européia, liderada por italianos e espanhóis, os quais se dirigiram mais para os centros urbanos; enquanto os franceses, ingleses e belgas se localizaram em povoados agrícolas. A população que era estimada em 1800 em 2.492.000 habitantes, em 1914 estava em 7.885.000 habitantes. ROMERO, Luis A. Breve história contemporánea de Argentina. Buenos Aires: Fondo de Cultura Económica, 1994, p. 27. 
Em face às tensões culturais, em 1926, são publicadas novas edições de Martín Fierro de José Hernández, com o fim de reafirmar a memória coletiva do tipo social do gaúcho e preservar a unidade cultural.

Nos folhetins, o espaço urbano passa a ser rotulado como caótico e o cosmopolitismo é condenado pela instabilidade que produz na sociedade argentina. Assim, surgem inúmeros centros de tradições populares, nos quais os gaúchos são resgatados e consagrados como heróis, aprofundando as tensões com os intelectuais nacionalistas modernos que procuram construir as representações simbólicas do país e resgatar a memória coletiva, tendo como cenário a cidade. ${ }^{45} \mathrm{O}$ grupo da revista Martín Fierro do qual Xul participa, defende a integração do imigrante e a construção de uma identidade que tem por base as tradições urbanas.

\section{Considerações finais}

Xul e Torres-García, dois artistas de vivência cosmopolita que tiveram oportunidade de morar em grandes centros urbanos e entrar em contato com as vanguardas européias, apresentam concepções distintas a respeito do espaço urbano moderno. Se o uruguaio modifica o seu pensamento, o argentino mantém a sua visão de cidade até nas suas obras dos anos 50, quando ainda exalta a modernidade. Xul tem em vista a implantação da civilização moderna, sustentada sobretudo pela mecanização, a qual não se encontra consolidada em Buenos Aires, nos anos 20, apesar de sua expansão populacional, intelectual e espacial.

Em contraposição ao olhar de Xul sobre a cidade moderna, percebe-se que o artista uruguaio após a fase de euforia com a modernidade de Nova Iorque, procura a síntese entre o Humanismo e o Construtivismo, como uma espécie de reação aos excessos da mecanização, do materialismo e pragmatismo, e como meio de produzir o equilíbrio entre valores novos e tradicionais. Nos EUA, Torres-García passa a ter plena consciência do crescimento "monstruoso das cidades" e do "viver mecânico e sua arti-

45 PENHOS, Marta. Nativos em el salón. Artes plásticas e identidad em la primera mitad del siglo XX. In: PENHOS Y WECHSLER (coord.). Tras los pasos de la norma. Buenos Aires: Jilguero, 1999, p. 113. 
ficialidade". ${ }^{46}$ A partir desta experiência, ele procura construir um universo mais harmônico, apoiando-se em uma fala mítica sobre a cidade moderna, sem considerar as suas ambigüidades e esquecendo a sua vivência em Nova Iorque.

Apesar da diversidade de concepções desses dois artistas, eles têm em comum a aspiração de transformar o mundo através de suas especulações plásticas, bem como concretizar as projeções urbanas imaginárias, fundamentadas, em parte, na idéia de unidade. Essas projeções têm em vista a implantação de seus ideais sem considerar suas histórias, especificidades e condições. Daí suas falas terem o sentido mítico. Elas levam em conta determinados aspectos da cidade, porém excluem muitos outros importantes.

46 DUNCAN, Barbara. Joaquín Torres-García, 1874-1949. Austin: Museo de Arte de la Universidad de Texas, 1974, p. 141. 